\title{
MENDIDIK GENERASI MUDA MENGENAI PERKEMBANGAN KEHIDUPAN SOSIAL BUDAYA MASYARAKAT (PENGABDIAN DI DESA KANEKES KECAMATAN LEUWIDAMAR KABUPATEN LEBAK - BANTEN)
}

\author{
Yusuf Faisal Ali ${ }^{1}$ \\ ${ }^{1)}$ STKIP Pasundan Cimahi \\ email: yusuffaisalali2016@gmail.com
}

\begin{abstract}
Abstrak
Memberikan pengetahuan mengenai perkembangan kehidupan sosial budaya masyarakat pada generasi muda merupakan hal yang sangat penting. Kebudayaan adalah keseluruhan pemikiran dan benda yang dibuat atau diciptakan oleh manusia dalam perkembangan sejarahnya. Namun di era digital ini anak muda semakin rawan kehilangan jati diri mereka sehingga kurang tertarik dengan perkembangan kehidupan sosial budaya masyarakat yang di lingkungan mereka. Hal inilah yang menjadi ke khawatiran bersama mengenai masalah Ke-kurang tertarikan generasi muda dengan perkembangan kehidupan sosial budaya masyarakat. Oleh karena itu diperlukan wawasan mengenai perkembangan kehidupan sosial budaya masyarakat pada generasi muda. Hal inilah yang menjadi dasar program studi Pendidikan Pancasila dan Kewarganegaraan STKIP Pasundan Cimahi bekerjasama dengan masyarakat di Desa Kanekes Kecamatan Leuwidamar Kabupaten Lebak Banten untuk mengadakan pengabdian mengenai Memberikan pengetahuan mengenai perkembangan kehidupan sosial budaya masyarakat pada generasi muda. Kegiatan pengabdian masyarakat di di Desa Kanekes merupakan cara agar generasi muda mengenal dan memhamai perkembangan kehidupan sosial budaya masyarakat . Dengan adanya pengabdian ini, diharapkan generasi muda dapat mempunyai pemahaman yang baik mengenai perkembangan kehidupan sosial budaya masyarakat. Rekomendasi untuk kegiatan PKM berikutnya adalah terus melakukan usaha pengabdian pada bidang pengetahuan mengenai perkembangan kehidupan sosial budaya masyarakat pada generasi muda secara bertahap.
\end{abstract}

Kata kunci: Generasi Muda, Kehidupan Sosial, Budaya, STKIP Pasundan Cimahi

\begin{abstract}
Providing knowledge about the development of the socio-cultural life of the community to the younger generation is very important. Culture is all thoughts and objects created or created by humans in their historical development. However, in this digital era, young people are increasingly prone to lose their identity so that they are less interested in the development of the socio-cultural life of the people in their environment. This is a common concern regarding the problem of the younger generation's lack of interest in the development of the socio-cultural life of society. Therefore we need an insight into the development of the socio-cultural life of the community in the younger generation. This is the basis of the Pancasila and Citizenship Education study program STKIP Pasundan Cimahi in collaboration with the community in Kanekes Village, Leuwidamar District, Lebak Regency - Banten to hold services regarding providing knowledge about the development of the socio-cultural life of the community to the younger generation. Community service activities in Kanekes Village are a way for the younger generation to know and understand the development of the socio-cultural life of the community. With this dedication, it is hoped that the younger generation will have a good understanding of the development of the socio-cultural life of society. The recommendation for the next PKM activity is to continue to carry out community service efforts in the field of knowledge regarding the development of the sociocultural life of society in the younger generation in stages.
\end{abstract}

Keywords: Young Generation, Social Life, Culture, STKIP Pasundan Cimahi 


\section{PENDAHULUAN}

Era globalisasi mendorong berbagai perubahan pada manusia. Mir, Hassan, \& Qadri (2014) menyebukan jika globalisasi adalah fenomena yang kompleks dan dinamis. Karena kemajuan teknologi pada era globalisasi sangat cepat maka berbagai fenomena sosial yang menunjukan arah globalisasi semakin nyata.

Mendidik generasi muda mengenai perkembangan kehidupan sosial budaya masyarakat merupakan hal yang sangat penting. Hal ini karena generasi muda akan diajak Kembali mengenai jati diri mereka dan mengenali local wisdom. Hidayah, Feriandi, \& Saputro (2019) mengatakan bahwa pada era global, local wisdom dapat menjadi alternatif edukasi bagi warga negara. Sementara Malihah (2015) menyatakan bahwa generasi yang berkontribusi terhadap pembangunan merupakan generasi yang dibutuhkan.

Mengenalkan generasi muda pada kehidupan sosial budaya masyarakat adalah demi kepentingan bangsa dan negara. Proses mengenalkan budaya masyarakat dapat dilakukan melalui pendidikan, Retnasari, Suyitno, \& Hidayah (2019) mengemukakan bahwa tenaga pengajar dalam proses pembelajaran dapat memberikan unsur karakter.

Keberadaan generasi muda sebagai ujung tombak perubahan menjadi hal yang mendasari mengenai pengenalan mereka terhadap kehidupan sosial budaya masyarakat. Hal inilah yang mnejadi perhatian bahwa melakukan edukai pada generasi muda mengenai kehidupan sosial budaya masyarakat adalah hal yang mendesak, khususnya di era global.

STKIP Pasundan Cimahi bekerjasama dengan masyarakat di Desa Kanekes Kecamatan Leuwidamar Kabupaten Lebak - Banten dalam mengadakan pengabdian masyarakat mengenai perkembangan kehidupan sosial budaya masyarakat pada generasi muda.

Dalam rangka meningkatkan pengetahuan mengenai perkembangan kehidupan sosial budaya masyarakat pada generasi muda seperti yang telah disebutkan sebelumnya, maka dipandang penting kiranya memberikan pemahaman pada generasi muda mengenai perkembangan kehidupan sosial budaya masyarakat. Namun juga seperti yang telah dijelaskan sebelumnya terrdapat kendala dalam meningkatkan pengetahuan mengenai perkembangan kehidupan sosial budaya masyarakat pada generasi muda. Maka dari itu, dpat diidentifikasikan bahwa permasalahan dalam meningkatkan pengetahuan mengenai perkembangan kehidupan sosial budaya masyarakat pada generasi muda adalah :

1. Kurangnya ketertarikan generasi muda mengenai perkembangan kehidupan sosial budaya masyarakat

2. Kurang akses generasi muda mengenai perkembangan kehidupan sosial budaya masyarakat

3. Adanya potensi pada generasi muda untuk dapat meningkatkan pengetahuan mengani perkembangan kehidupan sosial budaya masyarakat

Pengabdian ini ditujuakan pada mahasiswa agar mereka memiliki pengetahuan mengenai perkembangan kehidupan sosial budaya masyarakat

\section{METODE}

Agar terlaksana dan mencapai tujuan, pengabdian masyarakat ini menggunakan metode:

a. Pendidikan Masyarakat, yaitu berupa in-house training yang bertujuan meningkatkan pemahaman serta kesadaran mengani perkembangan kehidupan sosial budaya masyarakat pada generasi muda

b. Konsultasi, yaitu aktivitas berupa analisis kebutuhan dalam masyarakat diselesaikan melalui sinergisme dengan Perguruan Tinggi. Dalam hal ini adalah STKIP Pasundan Cimahi. 


\section{HASIL DAN PEMBAHASAN} ini adalah:

Sesuai dengan program pengabdian yang telah direncanakan.maka target luaran pengabdian

1. Produk: terbentuknya pengetahuan mahasiswa mengenai perkembangan kehidupan sosial budaya masyarakat khususnya di Desa Kanekes Kecamatan Leuwidamar Kabupaten Lebak - Banten

2. Jasa: tersosialisasinya mahasiswa mengenai perkembangan masyarakat dan budaya di Desa Kanekes Kecamatan Leuwidamar Kabupaten Lebak - Banten melalui in-house training dan konsultasi

Masyarakat Kanekes atau orang Baduy/Badui adalah suatu kelompok masyarakat adat subetnis Sunda di wilayah Kabupaten Lebak, Banten. Lokasi Suku Baduy tepatnya berda di kaki pegunungan Kendeng di desa Kanekes, Kecamatan Leuwidamar, Kabupaten LebakRangkasbitung, Banten, berjarak sekitar 40 km dari kota Rangkasbitung Populasi mereka sekitar 5.000 hingga 8.000 orang, dan mereka merupakan salah satu suku yang menerapkan isolasi dari dunia luar. Selain itu mereka juga memiliki keyakinan tabu untuk difoto, khususnya penduduk wilayah Baduy dalam. Wilayah suku baduy sendiri terbagi kedalam 2 daerah yaitu suku baduy dalam dan baduy luar. Suku baduy dalam merupakan suku baduy yang benar-benar masih menjaga pikukuhnya sedangkan suku baduy luar merupakan suku baduy yang sudah berbaur dengan masyarakat sekitarnya.

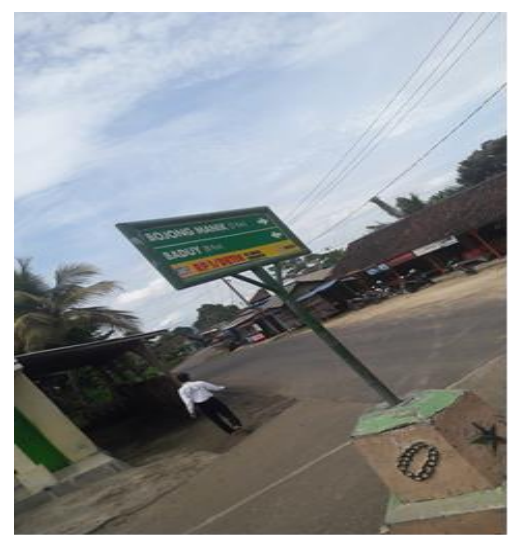

Gambar 1: Lokasi Pengabdian di Desa Kanekes Kecamatan Leuwidamar Kabupaten Lebak Banten

Lebih jelasnya, berikut adalah kerangka pikir penabdian masyarakat mendidik generasi muda mengenai perkembangan kehidupan sosial budaya masyarakat (Pengabdian di Desa Kanekes Kecamatan Leuwidamar Kabupaten Lebak - Banten): 


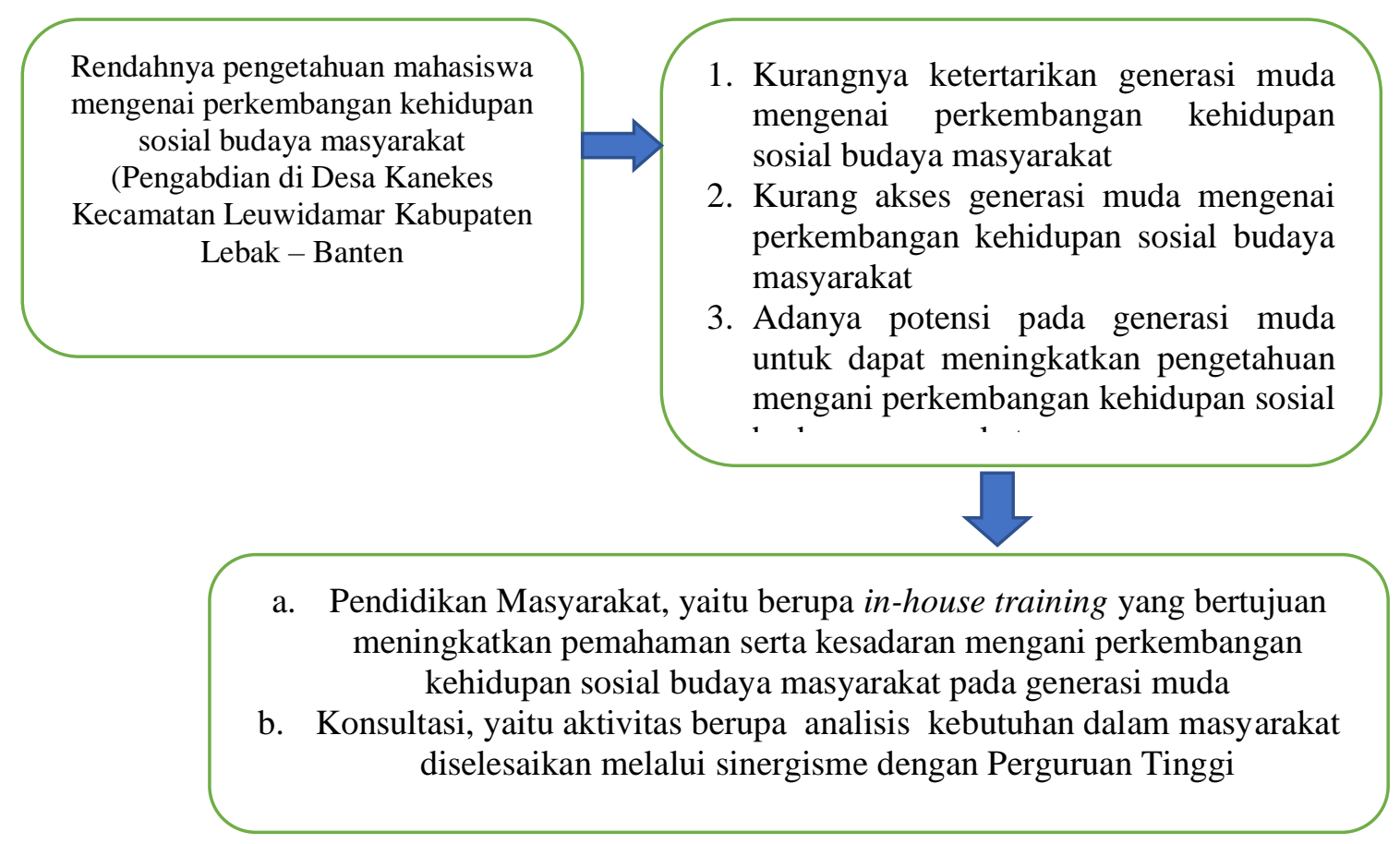

Gambar 2: Gambar kerangka pikir penabdian masyarakat mendidik generasi muda mengenai perkembangan kehidupan sosial budaya masyarakat (Pengabdian di Desa Kanekes Kecamatan Leuwidamar Kabupaten Lebak - Banten)

Wirawan (2011) mengemukakan bahwa kegiatan adalah aktivitas yang dirancang dan dilaksanakan dalam tempo yang terbatas. Maka dari itu, Pada pendidikan masyarakat, yaitu berupa in-house training yang bertujuan meningkatkan pemahaman serta kesadaran mengani perkembangan kehidupan sosial budaya masyarakat pada generasi muda. Aktivitas in-house training di Desa Kanekes Kecamatan Leuwidamar Kabupaten Lebak - Banten dilakukan dengan tujuan mengoptimalkan potensi mahasiswa. Hal tersebut tim pengabdian lakukan dengan berdasarkan pada pendapat Sujoko (2012) bahwa in-house training adalah pelatihan yang bertujuan meningkatkan kompetensi dengan mengoptimalkan potensi yang ada.

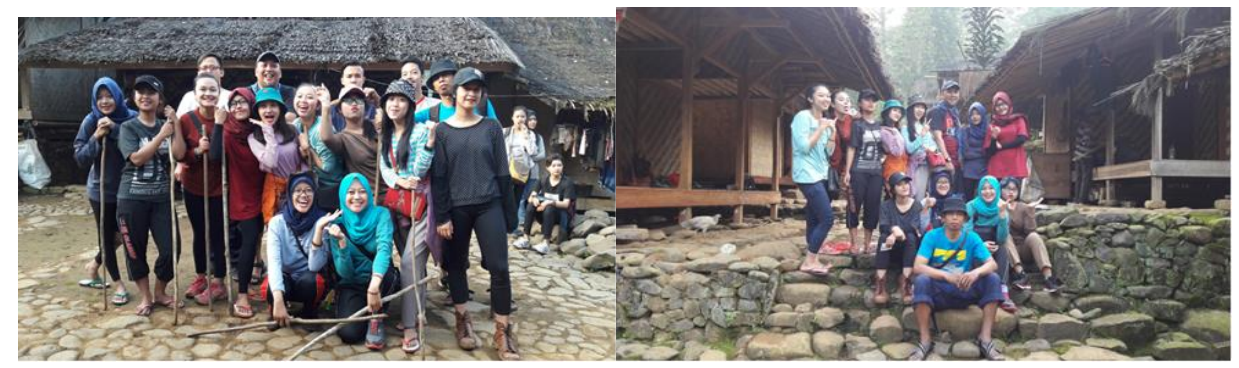

Gambar 3: Aktivitas di Desa Kanekes Kecamatan Leuwidamar Kabupaten Lebak - Banten

Kamil (2010) menjelaskan jika pelatihan adalah pemberdayaan antara indvidu yang haru sesuai dengan materi agar meningkatkan keterampilan dan pendapatan. Maka pada konsultasi ini yaitu aktivitas berupa analisis kebutuhan dalam masyarakat diselesaikan melalui sinergisme dengan Perguruan Tinggi, Dalam hal ini adalah STKIP Pasundan Cimahi.

STKIP Pasundan Cimahi sebagai salah satu Perguruan Tinggi di Kota Cimahi mmeiliki misi menjadi LPTK yang unggul dalam bidang pendidikan pada tahun 2040. Maka dari itu, melalui aktivitas pengabdian masyarakat mendidik generasi muda mengenai perkembangan kehidupan sosial budaya masyarakat (Pengabdian di Desa Kanekes Kecamatan Leuwidamar Kabupaten Lebak - Banten) menjadi salah satu upaya bagi STKIP Pasundan Cimahi untuk dapat menghasilkan professional muda dalam pendidikan yang unggul. 


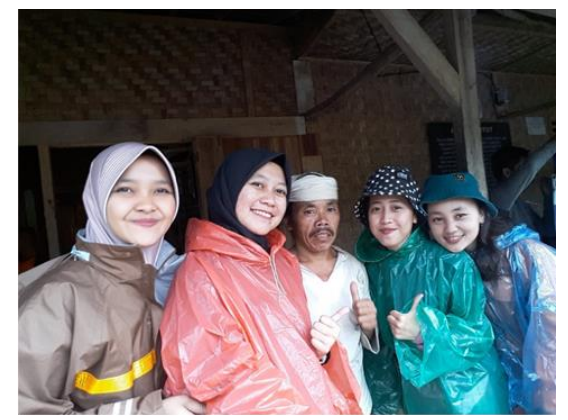

Gambar 4: Interaksi dengan masyarakat di Desa Kanekes Kecamatan Leuwidamar

\section{SIMPULAN} Kabupaten Lebak - Banten

Tingkat ketercapaian target kegiatan di lapangan mengenai memberikan pengetahuan mengenai perkembangan kehidupan sosial budaya masyarakat pada generasi muda di Desa Kanekes Kecamatan Leuwidamar Kabupaten Lebak - Banten adalah sangat baik. Tantangan yang dihadapi dengan metode pengabdian yang diterapkan adalah keterbatasan waktu, biaya dan tenaga di lokasi pengabdian. Dampak dan manfaat kegiatan yang telah dilaksanakan adalah 1) generasi muda dapat memahami mengenai perkembangan kehidupan sosial budaya masyarakat, 2) generasi muda dapat pengalaman mengani kehidupan sosial budaya masyarakat di Desa Kanekes Kecamatan Leuwidamar Kabupaten Lebak - Banten. Rekomendasi untuk kegiatan PKM berikutnya adalah terus melakukan usaha pengabdian pada bidang pengetahuan mengenai perkembangan kehidupan sosial budaya masyarakat pada generasi muda secara bertahap.

\section{SARAN}

Untuk STKIP Pasundan Cimahi disarankan untuk melakukan kelanjutan mengenai pengabdian di Desa Kanekes Kecamatan Leuwidamar Kabupaten Lebak - Banten.

\section{UCAPAN TERIMA KASIH}

Ucapan terima kasih diucapkan pada masyarakat di Desa Kanekes Kecamatan Leuwidamar Kabupaten Lebak - Banten yang telah bersedia bekerjasama membantu pelaksanaan kegiatan pengabdian. Terimakasih kepada LPPM (Lembaga Penelitiandan Pengabdian Masyarakat) STKIP Pasundan Cimahi atas izinnya dalam pelaksanaan kegiatan pengabdian di Desa Kanekes Kecamatan Leuwidamar Kabupaten Lebak - Banten.

\section{DAFTAR PUSTAKA}

Hidayah, Y., Feriandi, Y. A., \& Saputro, E. A. V. (2019). Transformasi Kearifan Lokal Jawa Dalam Pendidikan Karakter Sekolah Dasar. AULADUNA: Jurnal Pendidikan Dasar Islam, 6(1). https://doi.org/10.24252/auladuna.v6i1a6.2019

Kamil, M. (2010). Model Pendidikan dan Pelatihan. Bandung: Alfabeta.

Malihah, E. (2015). An ideal Indonesian in an increasingly competitive world: Personal character and values required to realise a projected 2045 'Golden Indonesia.' Citizenship, Social and Economics Education, 14(2), 148-156. https://doi.org/10.1177/2047173415597143

Mir, U., Hassan, D. S. M., \& Qadri, M. (2014). Understanding Globalization and its Future: An Analysis, 34, 607-624.

Retnasari, L., Suyitno, S., \& Hidayah, Y. (2019). Penguatan Peran Taman Pendidikan Al-Quran (TPQ) Sebagai Pendidikan Karakter Religius. Jurnal Solma, 8(1), 32-38. https://doi.org/10.29405/solma.v8i1.2968

Sujoko, A. (2012). Peningkatan Kemampuan Guru Mata Pelajaran Melalui In House Training. Jurnal Pendidikan Penabur-No.18 tahun ke-11/Juni.

Wirawan. (2011). Evaluasi Teori Model Standar Aplikasi dan Profesi, Contoh Aplikasi Evaluasi Program: Pengembangan Sumber Daya Manusia, Program Nasional Pemberdayaan Masyarakat (PNPM) Mandiri Pedesaan, Kurikulum, Perpustakaan, dan Buku Tes. Jakarta: Raja Grafindo Persada. 